\title{
Design and Implementation of Energy Efficiency in HVAC Systems Based on Robust PID Control for Industrial Applications
}

\author{
Muharrem Imal \\ Mechanical Engineering Department, Kahramanmaras Sutcu Imam University, 46100 Kahramanmaras, Turkey \\ Correspondence should be addressed to Muharrem Imal; muharremimal@ksu.edu.tr
}

Received 11 October 2014; Revised 16 March 2015; Accepted 23 March 2015

Academic Editor: Qing-An Zeng

Copyright (C) 2015 Muharrem Imal. This is an open access article distributed under the Creative Commons Attribution License, which permits unrestricted use, distribution, and reproduction in any medium, provided the original work is properly cited.

Energy efficiency in heating, ventilating, and air-conditioning (HVAC) systems is a primary concern in process projects, since the energy consumption has the highest percentage in HVAC for all processes. Without sacrifice of thermal comfort, to reset the suitable operating parameters, such as the humidity and air temperature, would have energy saving with immediate effect. In this paper, the simulation-optimization approach described the effective energy efficiency for HVAC systems which are used in industrial process. Due to the complex relationship of the HVAC system parameters, it is necessary to suggest optimum settings for different operations in response to the dynamic cooling loads and changing weather conditions during a year. Proportionalintegral-derivative (PID) programming was developed which can effectively handle the discrete, nonlinear and highly constrained optimization problems. Energy efficiency process has been made by controlling of alternative current (AC) drivers for ventilation and exhaust fans, according to supplied air flow capacity and differential air pressure between supplied and exhaust air. Supervisory controller software was developed by using programmable controllers and human machine interface (HMI) units. The new designed HVAC control system would have a saving potential of about $40 \%$ as compared to the existing operational settings, without any extra cost.

\section{Introduction}

Several studies have been carried out in the past few years for minimizing the energy consumption related with the control of HVAC systems. HVAC units used in industrial processes have high energy consumptions. It has been estimated that $40 \%$ of total energy is consumed in HVAC systems for fabric plants. So, the energy efficiency is the most important role played in HVAC systems. Therefore, a well-designed energy control system improves the energy efficiency [1-6].

In recent years, many researchers have studied dynamic models of HVAC systems and their components using theoretical or experimental approaches for buildings on the ground. However, ground buildings and semiopen built space have become major spaces of use for metropolitan residents $[7,8]$. While many control strategies have been suggested in previous reports [9], to the best of our knowledge only a few studies have been conducted on the quantification and comparison of control strategies in process industry for industrial plants.

The HVAC systems are composed of a large number of subsystems; each of them may exhibit nonlinear characteristics. The parameters of the systems change with weather, load, and process occupancy. In many situations, the exact model of the system cannot be obtained, but the approximate model can be derived. These complexities can be eliminated by using a well-designed control technique, operating strategies, and optimum conditions of different HVAC equipment and subsystems.

Modern control methods such as proportional-integralderivative (PID) controllers are widely used in the process industry; their effectiveness is often limited due to poor tuning; on the other hand they can be easily implemented due to low cost and being reliable in harsh field conditions. The PID 
control techniques can be used on model-free and modelbased control systems [5-8].

It is very useful to consider the simulation-optimization approach in response to the problem of effective energy efficiency. In the context of the plant services and HVAC systems, a variety of transfer functions have been developed according to the problems, like all year around energy consumption, lifecycle cost, thermal comfort, plant scheduling, design parameters, routing, and distribution. In addition, there are increasing applications of the plant simulation models for decision making purpose, and a multicriterion optimization approach would be adopted for a number of changeable system capacities instead of a single solution which would be provided for decision making.

This paper describes a novel simulation-optimization technique that was applied to devise a reset scheme of air flow for air temperatures and differential air pressure for supply and exhaust air of the HVAC control system in fabric manufacturing plants in industry. The designed control system has been used in a fabric group which is one of the biggest fabric companies in Turkey. The whole system was firstly constructed by LUWA Corporation. The mechanical system was not changed, but the complete control system was removed and the new designed control system was placed instead of old conventional control system. After the designed control system was operated, the energy consumption decreased approximately $40 \%$ in the four unit plants. The energy efficiency has been carried out by the controlling of ventilation and exhaust driver inverters depending on differential air pressure between supply and exhaust air and air flow measurement for air changes per second. The controller system consists of the four programmable controller modules, four human machine interface (HMI) units, and computer systems. Every HVAC system has been controlled depending on four parameters: humidifier pump controller for humidification, fresh and bypass damper controllers for temperature control, exhaust fan controllers for stability of differential air pressure, and ventilation fan controllers for air flow capacity. These parameters were controlled by four loop PID controllers implemented in programmable controllers. Supervisory control software was developed to analyze and to control the whole system from a HMI interface. In addition, energy and mass balance equations are applied to derive a dynamic model of single-zone HVAC system and a simulation example has been proposed to investigate different PID control algorithms on the derived mathematical model of the controlled zone. The results from the proposed simulation-optimization technique were used to evaluate the existing operational settings and suggest the possible saving potential from the newly optimized information.

\section{Material and Method}

2.1. System Structure. The system has such main components as an air conditioned room of fabric plant, the fresh, bypass, and exhaust air dampers, damper actuators, ventilation and exhaust air fans, humidifiers pumps, driver inverters for

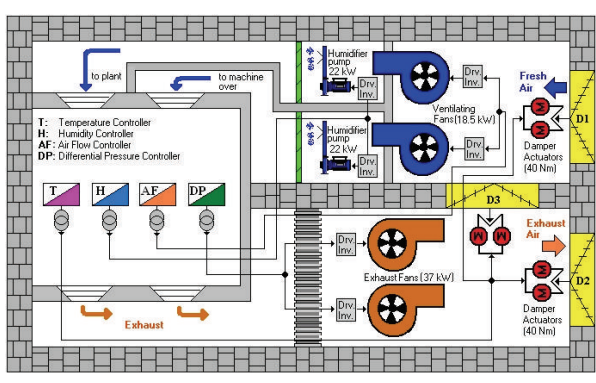

FIGURE 1: General block diagram of the controlled HVAC system for plants.

humidification, temperature, humidity, air flow, and differential air pressure sensors and controllers. Figure 1 shows the general schematic diagram of the single-zone HVAC controlled system for fabric plants. The ideal temperature and humidity levels are generally $25^{\circ} \mathrm{C}$ and $70 \%$, respectively, in fabric air condition systems.

Cooling process is performed by utilizing the cold water used for humidification by mixing fresh air supplied from outdoor damper in the fabric air condition systems. Heating processes have been made by circulation of indoor air that generated heat from machines, lights, and people, using bypass dampers. According to desired temperature value, the temperature controller directs the damper actuators which are BELIMO trademarked proportional servomotors having the $40 \mathrm{Nm}$ torque, 2 to $10 \mathrm{VDC}$ control signal, and feedback signals. If the controlled zone temperature is to be raised, the controller commands to the bypass dampers in the direction of opening position, and conversely the fresh and exhaust dampers in direction of closing position. The rate of opening and closing values has to be the same values to equilibrate air pressure between indoor and outdoor.

Humidity controlling has been performed by using humidifier pumps and its driver inverters having the power of $22 \mathrm{~kW}$, spray water flow rate of $78 \mathrm{~m}^{3} / \mathrm{h}$, and nozzle pressure of 2.1 bar. The task of the humidifier pumps is to provide necessary humidity by vaporizing water supplied from water pool. The vaporized water has been mixed by the supplied air from ventilating fans and then it has been carried to indoor space for humidification.

Air flow controller unit controls the desired volume flow rate of supplied air which is determined from the air changes per second for the need of controlled plant. The air flow capacity changes depending on the plant's size, the number of machines, and the type of the plant such as fabric or yarn. Air flow controller has been done by the ventilation fans with the power of $18.5 \mathrm{~kW}$ and the capability of $103.000 \mathrm{~m}^{3} / \mathrm{h}$ air flow capacity. The desired air flow capacity is determined by the expert operators.

The air pressure difference between indoor and outdoor has to be equilibrated in the product type HVAC systems. The differential pressure controller compensates the air pressure based upon the differential pressure transmitter using the $37 \mathrm{~kW}$ exhaust fan drivers. Humidifier pumps, nozzles, fresh air dampers, exhaust air dampers, ventilating, and exhaust 

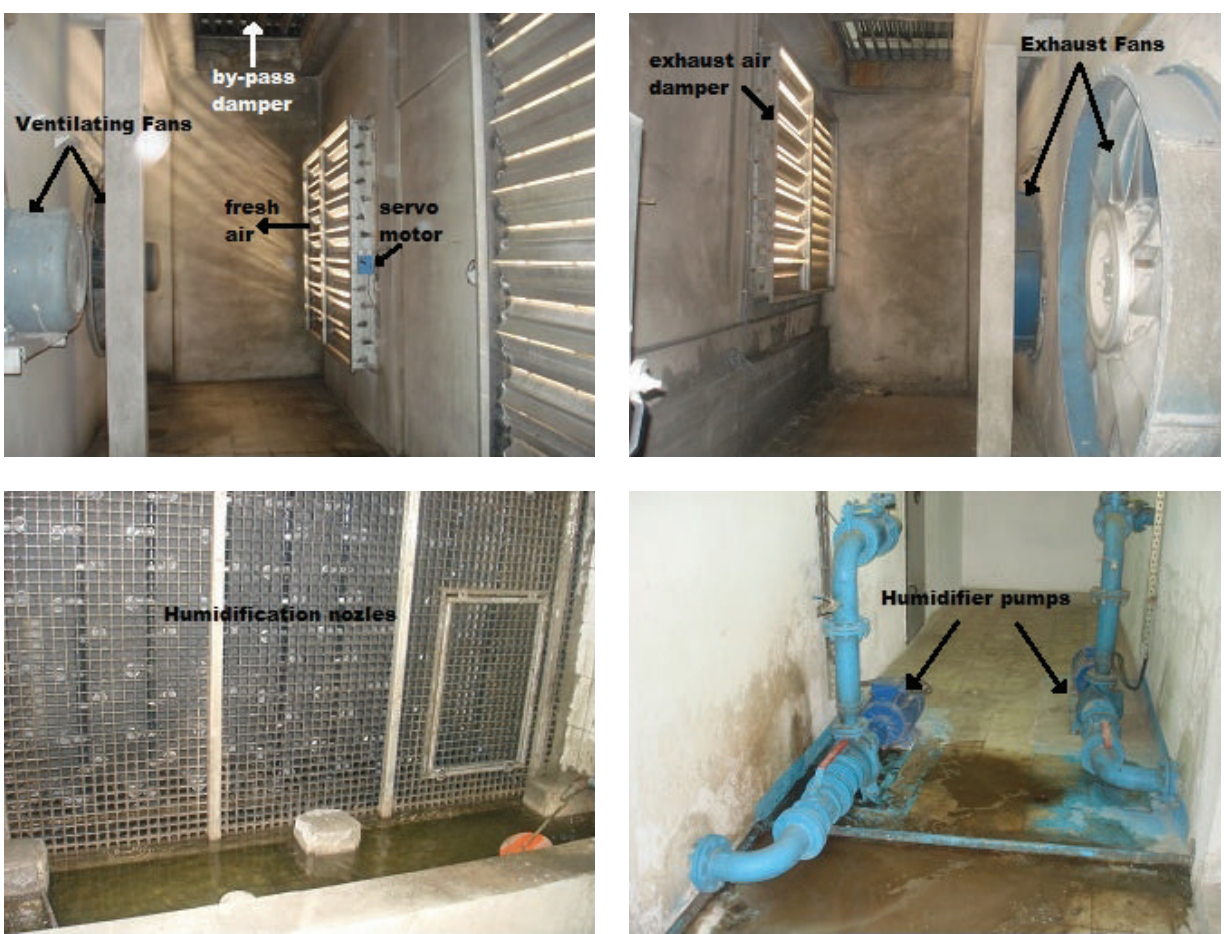

Figure 2: General view of humidification and air supplier units of controlled system.

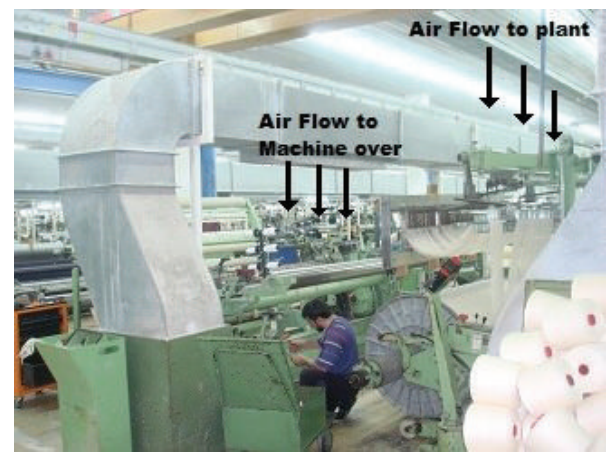

Figure 3: The machine over and the plant air flow channels of the controlled zone.

fans of controlled system have been shown in Figure 2. The supplied air has been directed to different air channels as shown in Figure 3. These channels are the machine over and the plant channels, respectively. These channels are controlled by the different controller units as shown in Figure 1.

The formerly designed controller by LUWA incorporation had only temperature and humidity controller. Ventilation and exhaust fans had operated at fixed rotation speed. Energy consumed by the ventilation and exhaust fans corresponds to $40 \%$ of total energy spent in a plant. To decrease energy consumption, the driver inverters have been used for speed control of ventilation and exhaust fans drivers according to desired air flow capacity and differential air pressure in the designed control system.
The old conventional and the new designed controller system have been shown in Figure 4 for a single zone of HVAC system.

Four independent controllers were designed for each HVAC unit as shown in Figure 5. These controllers were connected by the Ethernet communication units. The whole system has been controlled by the developed supervisory control software from a single control point as shown in Figure 6. Each unit has an operator panel and the set points can be entered from this panel or HMI unit. The developed supervisory control software is able to perform online data visualization, data storage, data trends, and animation graphs and full control of complete system.

2.2. Dynamic Control Model of HVAC System. Since the HVAC zones have the structure of complex thermal system structure and the actual air-conditioning system is more variable, it is very difficult to determine for its exact model, but the approximate overall dynamic model of a single-zone HVAC system consisting of all its component models can be derived. The whole plant model could reflect the HVAC system with complete dynamic operation of different equipment and subsystems for the cooling demand throughout the yearly operating hours. In the hourly control and operation of different equipment and subsystems, there were four sets of input data files: total and space loads, weather conditions, water temperature, and that specifically for the component model of water-cooled air conditioning systems. The total cooling load was used to determine the water temperature and water pump pressure in operation. In addition, enthalpy control 


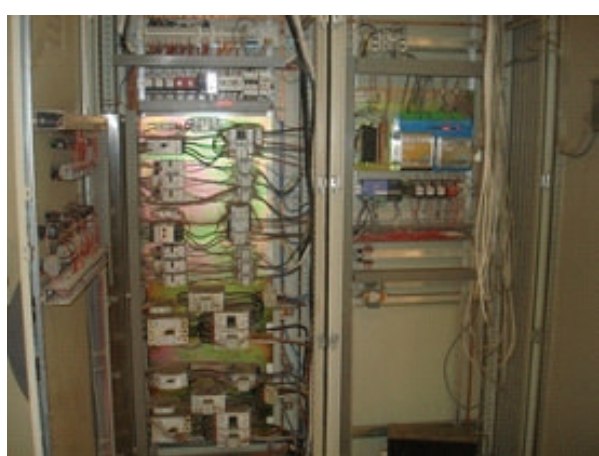

(a)
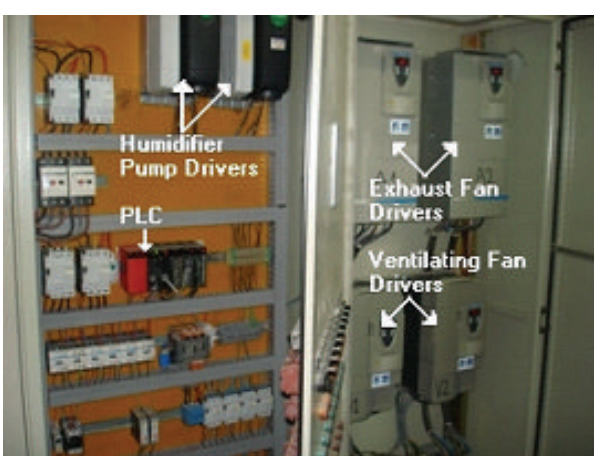

(b)

FIGURE 4: (a) The old conventional control system for single zone, (b) the new designed control system for single zone.
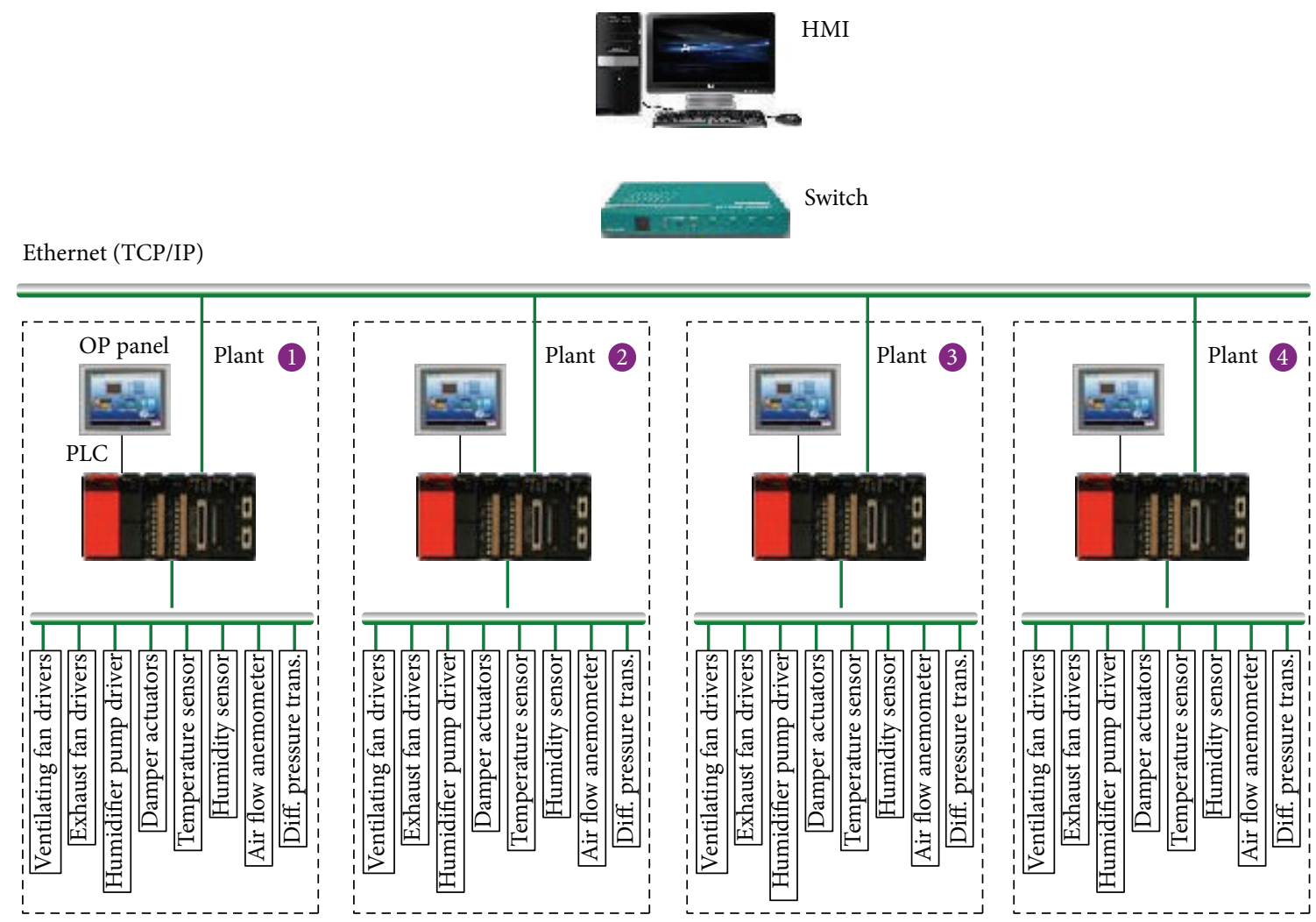

FIGURE 5: The structure of the designed control system.

was utilized to decide the implementation of free cooling mode, which would call for the free cooling fan in operation, with the same speed of the other operating fans. This dynamic control and operation algorithm was essential to provide the necessary system response to different loading and climatic conditions, although this would increase the degree of the nonlinear, constrained, and discrete nature of the system performance, in particular to the energy efficiency of both the water side and air side systems. The HVAC optimization problem hence requires an effective method that could handle the nonlinear, discrete, and highly constrained characteristics.
2.3. Zone Model. According to thermodynamic energy balance principles, a simple energy equation for a single-zone HVAC system can be written in (1)

$$
Q_{\text {input }}+Q_{\text {generation }}=Q_{\text {out }}+Q_{\text {accumulation }}+Q_{\text {consumption }} \text {, }
$$

where $Q_{\text {input }}$ is heat from supply air input, $Q_{\text {generation }}$ is generated heat from people, woven machines, light, and so forth, $Q_{\text {out }}$ is heat from exhaust air, $Q_{\text {accumulation }}$ is indoor space heat, and $Q_{\text {consumption }}$ is dissipated heat from indoor to outdoor. 

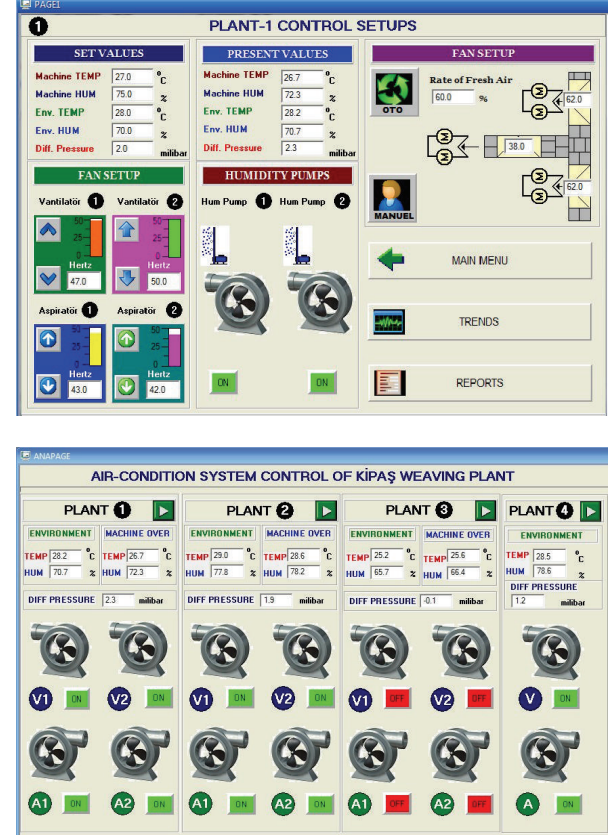

FIGURE 6: The developed program interface for control and analysis from one HMI unit.

The heat equation is derived from the first law of thermodynamics and conservation of energy. Any change in energy $\Delta Q$ is proportional to the change in temperature $\Delta T$. That is,

$$
\Delta Q=f_{a} c_{p} \rho_{a} \Delta T,
$$

where $f_{a}\left(\mathrm{~m}^{3} / \mathrm{s}\right)$ is volume flow rate of air, $c_{p}\left(\mathrm{~kJ} / \mathrm{kg} \cdot{ }^{\circ} \mathrm{C}\right)$ is the constant pressure specific heat capacity of air, and $\rho_{a}\left(\mathrm{~kg} / \mathrm{m}^{3}\right)$ is the mass density of air. From the thermodynamic heat equations, the fresh and exhaust heat equations can be written as

$$
\begin{aligned}
Q_{\text {input }} & =f_{\mathrm{sa}} c_{\mathrm{pa}} \rho_{a} T_{\mathrm{sa}}, \\
Q_{\text {out }} & =f_{\mathrm{sa}} c_{\mathrm{pa}} \rho_{a} T_{i},
\end{aligned}
$$

where $f_{\text {sa }}\left(\mathrm{m}^{3} / \mathrm{s}\right)$ is volume flow rate of supplied air:

$$
\begin{aligned}
Q_{\text {generation }} & =Q_{\text {room }}, \\
Q_{\text {accumulation }} & =\rho_{a} c_{\mathrm{pa}} v_{z} \frac{d T_{i}}{d t}, \\
Q_{\text {consumption }} & =\frac{v_{z} c_{\mathrm{pa}} \mathrm{ACH}}{3600}\left(T_{i}-T_{0}\right),
\end{aligned}
$$

where $Q_{\text {room }}(\mathrm{W})$ is heat gains from machines, light, people, and so forth and $v_{z}\left(\mathrm{~m}^{3}\right)$ is volume of the zone. ACH is the air changes per hour. There are three modes of consumption heat from indoor to outdoor: conduction, convection, and radiation. The convection heat equation is defined as follows:

$$
\begin{aligned}
Q_{\text {convection }} & =h \Delta T, \\
Q_{\text {conduction }} & =k \Delta T, \\
Q_{\text {radiation }} & =\varepsilon \sigma(\Delta T)^{4},
\end{aligned}
$$

where $h$ is convection heat transfer coefficient $\left(\mathrm{W} / \mathrm{m}^{2} \cdot{ }^{\circ} \mathrm{C}\right), k$ is conduction heat transfer coefficient $\left(\mathrm{W} / \mathrm{m} \cdot{ }^{\circ} \mathrm{C}\right), \varepsilon$ is emissivity constant, and $\sigma$ is Boltzmann constant $\left(\mathrm{W} / \mathrm{m}^{2} \cdot{ }^{\circ} \mathrm{C}\right)$. The heat dissipates into the zone mostly through the conduction heat, so that the convection and radiation heats can be ignored. The temperature zone equation can be written as

$$
\begin{aligned}
v_{z} c_{\mathrm{pa}} \rho_{a} \frac{d T_{i}}{d t}= & \frac{v_{z} c_{\mathrm{pa}} \mathrm{ACH}}{3600}\left(T_{0}-T_{i}\right) \\
& +f_{\mathrm{sa}} c_{\mathrm{pa}} \rho_{a}\left(T_{\mathrm{sa}}-T_{i}\right)+Q_{\text {room }} .
\end{aligned}
$$

Temperature controlling has been performed by the three damper controller units in the fabric HVAC systems which are fresh damper $D 1$, exhaust damper $D 2$, and return air damper D3. Therefore, supply air volume flow rate is composed of mixing the returned air from inner (exhaust air) zone and outdoor air. This mixing equation can be written from mass balance equation

$$
m_{r} c_{\mathrm{pa}} T_{i}+m_{o} c_{\mathrm{pa}} T_{o}=m_{s} c_{\mathrm{pa}} T_{\mathrm{sa}}
$$

where $m_{r}, m_{o}$, and $m_{s}$ are mass flow rates of the return, outdoor, and supplied airs, respectively. This condition has to be fulfilled by the controlling of these three damper positions. If the position of $D 1$ and $D 2$ dampers is opened at the rate of $40 \%$, the position of D3 damper must be opened at the rate of $60 \%$. That is, $D 1=D 2=(100-D 3)$. Humidification is a mass transfer process of water vapor to atmospheric air, which results in an increase of water vapor in the mixture. Humidifier model is the same as temperature model and can be derived from mass and energy balance principles as given in [4]

$$
C_{h} \frac{d T_{h}}{d t}=f_{\mathrm{sa}} c_{\mathrm{pa}}\left(T_{\mathrm{sa}}-T_{h}\right)+\alpha_{h}\left(T_{o}-T_{h}\right)
$$

where $C_{h}$ is overall thermal capacitance of the humidifier, $T_{h}$ is supply air temperature (in humidifier), and $\alpha_{h}$ is overall transmittance area factor of the humidifier $\left(\mathrm{kJ} / \mathrm{s} \cdot{ }^{\circ} \mathrm{C}\right)$. Similarly, the rate change of moisture content in the zone is equal to the difference between the vapor added to and removed from the zone. Therefore, humidity zone equation can be written in

$$
v_{z h} \frac{d W_{h}}{d t}=f_{\mathrm{sa}}\left(W_{\mathrm{sa}}-W_{h}\right)+\frac{h(t)}{\rho_{a}}
$$

where $v_{z h}$ is the volume of humidifier, $W_{h}$ is supply air humidity ratio (in humidifier) in $\mathrm{kg} / \mathrm{kg}$ (dry air), $W_{\text {sa }}$ is humidity ratio of supply air (to the humidifier) in $\mathrm{kg} / \mathrm{kg}$ (dry air), and $h(t)$ is the rate of moisture air produced in air humidifier. 
In order to find the transfer function of the controlled zone, the temperature zone (6)-(7) should be rearranged according the parameters of $T_{i}$ and $T_{o}$ :

$$
\begin{gathered}
v_{z} c_{\mathrm{pa}} \rho_{a} \frac{d T_{i}}{d t}+\left(\frac{v_{z} c_{\mathrm{pa}} \mathrm{ACH}}{3600}+f_{\mathrm{sa}} c_{\mathrm{pa}} \rho_{a}\right) T_{i} \\
=\frac{v_{z} c_{\mathrm{pa}} \mathrm{ACH}}{3600} T_{0}+f_{\mathrm{sa}} c_{\mathrm{pa}} \rho_{a} T_{\mathrm{sa}}+Q_{\mathrm{room}}, \\
v_{z} c_{\mathrm{pa}} \rho_{a} \frac{d T_{i}}{d t}+\left(\frac{v_{z} c_{\mathrm{pa}} \mathrm{ACH}}{3600}+f_{\mathrm{sa}} c_{\mathrm{pa}} \rho_{a}\right) T_{i} \\
=\frac{v_{z} c_{\mathrm{pa}} \mathrm{ACH}}{3600} T_{0}+f_{\mathrm{sa}} c_{\mathrm{pa}} \rho_{a}\left(\frac{m_{r} T_{i}+m_{o} T_{0}}{m_{s}}\right) \\
+Q_{\text {room }}
\end{gathered}
$$

In order to simplify (11), $\tau$ and $k$ can be defined as follows:

$$
\begin{gathered}
\tau=\frac{3600 v_{z} \rho_{a} m_{s}}{m_{s}\left(v_{z} \mathrm{ACH}+3600 f_{\mathrm{sa}} \rho_{a}\right)-3600 f_{\mathrm{sa}} \rho_{a} m_{r}}, \\
k=\frac{m_{s} v_{z} \mathrm{ACH}+3600 f_{\mathrm{sa}} \rho_{a} m_{o}}{m_{s}\left(v_{z} \mathrm{ACH}+3600 f_{\mathrm{sa}} \rho_{a}\right)-3600 f_{\mathrm{sa}} \rho_{a} m_{r}} .
\end{gathered}
$$

Finally, temperature zone (6) has been simplified as

$$
\tau \frac{d T_{i}}{d t}+T_{i}=k T_{o}+Q_{\text {room }}
$$

$Q_{\text {room }}$ is heat gains from machines, lights, people, and so forth and is a constant. The Laplace transform of (13) is expressed as

$$
\tau s T_{i}(s)-T_{i}(0)+T_{i}(s)=k T_{o}(s) .
$$

Because of the distance between supply air and the measurement point of temperature, there is pure delay time $(L)$ in the process. The plant heat transfer function is expressed as follows:

$$
G_{p}(s)=\frac{T_{i}(s)}{T_{o}(s)}=\frac{k e^{-L s}}{\tau s+1} .
$$

The system is considered as a first-order plus dead time (FOPDT) structure as shown in (15), where $k\left({ }^{\circ} \mathrm{C} \cdot \mathrm{s} / \mathrm{kg}\right)$ is the gain coefficient, $\tau$ is the time constant, and $L$ is the time delay of the controlled HVAC system.

2.4. Proportional-Integral-Derivative (PID) Control. The proportional-integral-derivative (PID) method is used to control the air flow and differential pressure by manipulating the fan speed of the ventilation system. PID controllers are widely employed in feedback control loops in most industrial process due to their simple structure, robustness, easy implementation, and good performance [10-15]. As indicated by the name, PID controllers consist of a proportional part, an integral part, and a derivative part as follows [16].

Proportional terms are

$$
U_{p}(t)=k_{c}\left(y_{s}(t)-y(t)\right) .
$$

Integral terms are

$$
U_{I}(t)=\frac{k_{c}}{\tau_{I}} \int_{o}^{t}\left(y_{s}(\tau)-y(\tau)\right) d t .
$$

Derivative terms are

$$
U_{D}(t)=k_{c} \tau_{d} \frac{d\left(y_{s}(t)-y(t)\right)}{d t},
$$

where $y_{s}(t)$ is the set point of the process output, $y(t)$ is the process output, and $U_{P}(t), U_{I}(t)$, and $U_{D}(t)$ are the controller outputs of the proportional, integral, and derivative parts, respectively. The constants $k_{c}, \tau_{I}$, and $\tau_{d}$ in (18) are the proportional gain, integral time, and derivative time, respectively. The total output of the PID controller is a summation of the three individual outputs in (16)-(18); that is,

$$
\begin{aligned}
U(t)= & U_{p}(t)+U_{I}(t)+U_{D}(t) \\
= & k_{c}\left(y_{s}(t)-y(t)\right) \\
& +\frac{k_{c}}{\tau_{I}} \int_{o}^{t}\left(y_{s}(\tau)-y(\tau)\right) d t \\
& +k_{c} \tau_{d} \frac{d\left(y_{s}(t)-y(t)\right)}{d t} .
\end{aligned}
$$

The three constants are the proportional gain, integral time, and derivative time, respectively.

$k_{c}, \tau_{I}$, and $\tau_{d}$ are usually called the parameters of the PID controller and should be determined under the dynamic condition of the process. So, the parameters for the improvement of the control performance have to be tuned.

2.5. Parameter Tuning. Up to now, numerous tuning methods have been developed, including the Ziegler-Nichols (Z$\mathrm{N})$ method, internal model control (IMC), and the integral of the time-weighted absolute value of the error tuning rule for a first-order plus time delay model (ITAE). In this paper, all three methods were implemented to tune the controller in the energy efficient HVAC control system. If the model of the system can be obtained, it is easy to design the PID controller for it.

The gain coefficients $k_{p}$ and $T_{i}$ can be achieved model based algorithms such as Ziegler-Nichols (Z-N) or variant of Z-N tuning rules (Chien-Hrones-Reswick (CHR), CohenCoon), Wang-Juang-Chan, Zhuang-Atherton optimum PID controller design, and internal model control (IMC) $[7-9,16-$ 19].

The response of an FOPDT model is shown in Figure 7. A large number of systems can be approximately modeled by (15). If the step response of the system can be experimentally measured, the parameters of the $k, L, T$, and a can be determined as shown in Figure 7(a). In the same way, if the frequency response of the system can be experimentally observed, the crossover frequency $\omega_{c}$ and critical gain $k_{c}$ can be obtained from the Nyquist plot as shown in Figure 7(b), where $a=K L / T$ and $T_{c}=2 \pi / \omega_{c}$. 


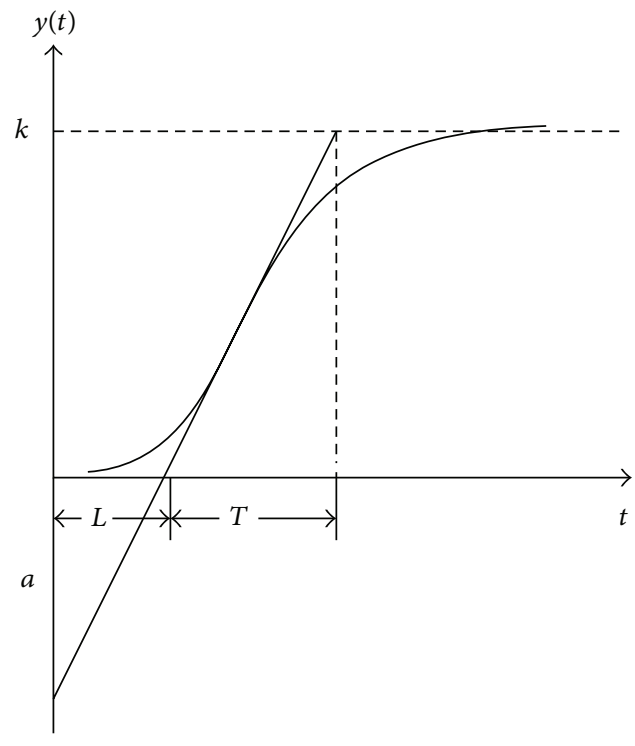

(a)

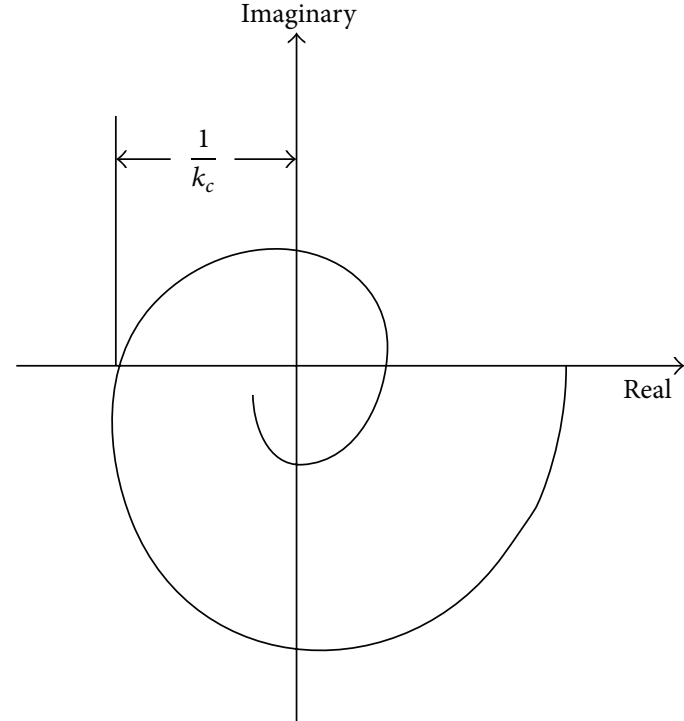

(b)

Figure 7: (a) The time response of FOPDT system, (b) the Nyquist plot of FOPDT system.

TABLE 1: Z-N tuning formulas.

\begin{tabular}{lcccccc}
\hline Controller type & \multicolumn{3}{c}{ Step response } & \multicolumn{3}{c}{ Frequency response } \\
& $k_{p}$ & $T_{i}$ & $T_{d}$ & $k_{p}$ & $T_{i}$ & $T_{d}$ \\
\hline $\mathrm{P}$ & $1 / a$ & & & $0.5 k_{c}$ & & \\
$\mathrm{PI}$ & $0.9 / a$ & $L / 0.3$ & & $0.45 k_{c}$ & $0.83 T_{c}$ & \\
$\mathrm{PID}$ & $1.2 / a$ & $2 L$ & $L / 2$ & $0.6 k_{c}$ & $0.5 T_{c}$ & $0.125 T_{c}$ \\
\hline
\end{tabular}

TABLE 2: CHR method tuning formulas.

\begin{tabular}{lcccccc}
\hline Controller type & \multicolumn{2}{c}{ Set point regulation } & \multicolumn{3}{c}{ Disturbance rejection } \\
& $k_{p}$ & $T_{i}$ & $T_{d}$ & $k_{p}$ & $T_{i}$ & $T_{d}$ \\
\hline $\mathrm{P}$ & $0.3 / a$ & & & $0.3 / a$ & & \\
$\mathrm{PI}$ & $0.35 / a$ & $1.2 T$ & & $0.6 / a$ & $4 L$ & $0.42 L$ \\
$\mathrm{PID}$ & $0.6 / a$ & $T$ & $0.5 L$ & $0.95 / a$ & $2.4 L$ & \\
\hline
\end{tabular}

The critical gain $k_{c}$ at the crossover frequency of $\omega_{c}$ is the first intersection of a Nyquist plot with the negative part of the real axis as shown in Figure 7(b):

$$
\frac{k\left(\cos \omega_{c} L_{i}-\omega_{c} T \sin \omega_{c L}\right)}{1+\omega_{c}^{2} T^{2}}=-\frac{1}{k_{c}} .
$$

The Z-N tuning method is a very useful empirical tuning formula. The PID controller parameters in Z-N tuning algorithms can be found from Table 1.

The Chien-Hrones-Reswick (CHR) method emphasizes the set point regulation or disturbance rejection. The CHR PID controller tuning formulas are summarized in Table 2 with the condition of no overshoot.

Another Z-N type tuning algorithm is the Cohen-Coon tuning formula. In this algorithm time constant $\tau$ is calculated as $\tau=L /(L+T)$ and PID parameters are tuned from Table 3 .

Wang-Juang-Chan tuning method is based on an optimum ITAE (the integral of time multiplied by absolute error)
TABLE 3: Cohen-Coon method tuning formulas.

\begin{tabular}{lccc}
\hline Cont. type & \multicolumn{3}{c}{ Set point regulation } \\
& $k_{p}$ & $T_{i}$ & $T_{d}$ \\
\hline $\mathrm{P}$ & $\frac{1}{a}\left(1+\frac{0.35 \tau}{1-\tau}\right)$ & \\
$\mathrm{PI}$ & $\frac{0.9}{a}\left(1+\frac{0.92 \tau}{1-\tau}\right)$ & $\frac{3.3-3 \tau}{1+1.2 \tau} L$ \\
$\mathrm{PID}$ & $\frac{1.35}{a}\left(1+\frac{0.18 \tau}{1-\tau}\right)$ & $\frac{2.5-2 \tau}{1-0.39 \tau} L$ & $\frac{0.37-0.37 \tau}{1-0.81 \tau} L$ \\
\hline
\end{tabular}

criterion. If the $k, L$, and $T$ parameters of the plant model are known, the controller parameters are given by

$$
\begin{gathered}
k_{p}=\frac{(0.7303+(0.5307 T / L))(T+0.5 L)}{k(L+T)}, \\
T_{i}=T+0.5 L,
\end{gathered}
$$


TABLE 4: Zhuang-Atherton method optimum tuning formulas.

\begin{tabular}{|c|c|c|c|c|c|c|}
\hline \multirow{2}{*}{$\begin{array}{l}L / T \\
\text { Criterion }\end{array}$} & \multicolumn{3}{|c|}{$0.1-1$} & \multicolumn{3}{|c|}{$1.1-2$} \\
\hline & ISE & ISTE & $\mathrm{IST}^{2} \mathrm{E}$ & ISE & ISTE & $\mathrm{IST}^{2} \mathrm{E}$ \\
\hline$a_{1}$ & 1.048 & 1.042 & 0.968 & 1.154 & 1.142 & 1.061 \\
\hline$b_{1}$ & -0.897 & -0.897 & -0.904 & -0.567 & -0.579 & -0.583 \\
\hline$a_{2}$ & 1.195 & 0.987 & 0.977 & 1.047 & 0.919 & 0.892 \\
\hline$b_{2}$ & -0.368 & -0.238 & -0.253 & -0.220 & -0.172 & -0.165 \\
\hline$a_{3}$ & 0.489 & 0.385 & 0.316 & 0.490 & 0.384 & 0.315 \\
\hline$b_{3}$ & 0.888 & 0.906 & 0.892 & 0.708 & 0.839 & 0.832 \\
\hline
\end{tabular}

$$
T_{d}=\frac{0.5 L T}{T+0.5 L}
$$

Zhuang and Atherton proposed the optimum PID controller design for various criteria. This method uses the integrated square error (ISE) function

$$
J_{n}(\theta)=\int_{0}^{\infty}\left[t^{n} e(\theta, t)\right]^{2} d t
$$

where $e(\theta, t) \triangleq r(t)-y(t, \theta)$ is the error signal of the closed loop system and $\theta \triangleq\left[k_{p}, T_{i}, T_{d}\right]^{T}$ is a vector containing the controller parameters. For the optimum PID controller parameters can be represented as

$$
\begin{gathered}
k_{p}=\frac{a_{1}}{k}\left(\frac{L}{T}\right)^{b_{1}}, \\
T_{i}=\frac{T}{a_{2}+b_{2}(L / T)}, \\
T_{d}=a_{3} T\left(\frac{L}{T}\right)^{b_{3}},
\end{gathered}
$$

where $(a, b)$ pairs are found from Table 4 according to the integral squared error (ISE) criterion, integral squared timeweighted error (ISTE) criterion, and the integral squared time-squared weighted error $\left(\mathrm{IST}^{2} \mathrm{E}\right)$ criterion.

The internal model control (IMC) algorithm is based on the fact that an accurate model of the process can lead to the design of a robust controller both in terms of stability and performance.

The first step in using the IMC (lambda) tuning correlations is to compute the closed loop time constant $\tau_{c}$. The closed loop time constant $\tau_{c}$ is the single adjustable IMC tuning parameter that allows the desired levels of performance and robust stability to be specified. IMC tuning PID parameters are chosen as the following equations:

$$
\begin{gathered}
k_{p}=\frac{L+2 T}{2 k\left(\tau_{c}+L\right)}, \\
T_{i}=T+\frac{L}{2}, \\
T_{d}=\frac{T L}{2 T+L},
\end{gathered}
$$

where $T_{c}$ is a design parameter that affects the tradeoff between performance and robustness.

\section{Simulation Method}

The objectives of this study are to assess the energy efficient control of HVAC system and to determine an optimal control strategy and its tuning parameters in order to maintain an efficient temperature, humidity, and pressure condition in an industrial fabric space. The first step, the temperature, humidity, and pressure control system is implemented using Matlab/Simulink. In the second step, four temperature control structures of the system are designed $\mathrm{Z}-\mathrm{N}$ based tuning algorithm model. The Z-N based tuning algorithm model establishes the kinetics of a process using a mathematical expression. One such expression is a transfer function that is the ratio of the Laplace transform of the process output and process input.

Totally four of the plants having the area of $22.000 \mathrm{~m}^{3}$ have been controlled by using PI controller. The parameters of the biggest zone are as follows.

The volume of the zone is $v_{z}=60 * 20.5 * 4.5=5535 \mathrm{~m}^{3}$, the volume flow rate of supplied air is $f_{\text {sa }}=18.05 \mathrm{~m}^{3} / \mathrm{s}$, the air density is $\rho_{a}=1.25 \mathrm{~kg} / \mathrm{m}^{3}$, the air specific heat is $c_{\mathrm{pa}}=$ $1.00 \mathrm{~kJ} / \mathrm{kg} \cdot{ }^{\circ} \mathrm{C}$, air change per hour is $\mathrm{ACH}=9$, mass flow rates of the return air is $m_{r}=8.66 \mathrm{~kg} / \mathrm{s}$, mass flow rates of the outdoor air is $m_{o}=5.78 \mathrm{~kg} / \mathrm{s}$, and mass flow rates of the supplied air is $m_{s}=14.44 \mathrm{~kg} / \mathrm{s}$. Substituting these parameters to the calculation of $\tau$ and $k$ constants, the transfer function of the plant is determined as follows:

$$
G_{p}(s)=\frac{1 e^{-20 s}}{300 s+1} .
$$

PI controller has been applied to the system having the feed forward transfer function of (25) as shown in Figure 8:

$$
G(s)=G_{p}(s) \cdot G_{c}(s)=K_{p}\left(1+\frac{1}{T_{i} s}\right) \cdot \frac{1 e^{-20 s}}{300 s+1} .
$$

Figure 9 shows the simulation of four different PID tuning methods for the unit step responses according to PID parameters given in Table 5 .

$\mathrm{Z}-\mathrm{N}$ and Cohen-Coon method has fast response time, but approximately $20 \%$ overshoot has occurred as shown in Figure 9. Wang-Juang-Chan and IMC tuning method have not seen overshoot, but rise time is more slowly comparing to other methods. It is well known that, the rise time depends on the proportional constant but overshoot depends on the integral time constant in PID controller. 
TABLE 5: Different types of PI controller parameters.

\begin{tabular}{lcc}
\hline Tuning methods & $k_{p}$ & $T_{i}$ \\
\hline Z-N & 13.5 & 66.6 \\
Cohen-Coon & 14.3 & 57.9 \\
Wang-Juang-Chan & 8.4 & 310 \\
IMC & 7.5 & 310 \\
\hline
\end{tabular}

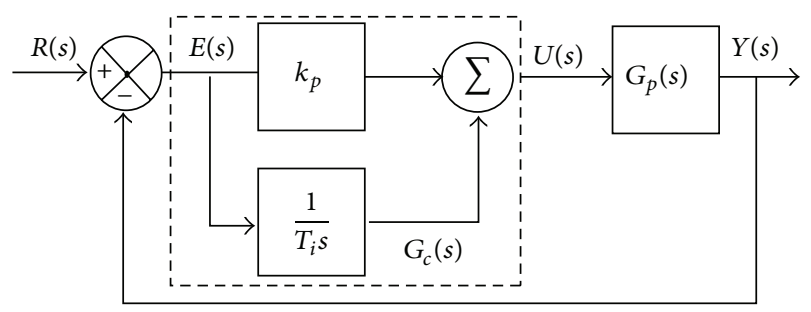

Figure 8: PI controller diagram for controlled parameters.

3.1. Experimental Results of the Real System Controller. Modern process control problems in the process industries are dominated by nonlinear, time-varying behavior, disturbances, and uncertainties. However, more than $90 \%$ of plants are controlled by the well-established PID controllers in industrial automation and process until today $[8,9]$. The control block diagram of the single-zone HVAC system is shown in Figure 8. Four types of PI controllers were designed to control temperature, humidity, air flow, and differential air pressure. Response of the control system depends on the outdoor temperature and humidity. If the outdoor temperature is high, decreasing the temperature of the zone will be very slow and limited. If the outdoor temperature is low, decreasing the temperature is very quick. Humidity controller is altered by temperature controller. If the system operates by the returned air, the increase in humidity becomes quickly. If the system runs at the fresh air position the humidity increment becomes slowly.

Totally 22 PI controllers were developed in a single programmable controller. These controller parameters were adjusted by using $\mathrm{Z}-\mathrm{N}$ tuning method. A software program was developed for quickly tuning the PID parameters of the controllers. The Z-N based tuning algorithm of the developed software is shown in Figure 10. The developed software is able to communicate with the programmable controller, selectable of control type (auto/manual control), and able to store control output data into database system and perform online analysis graphically as shown in Figure 11.

The complete HVAC system can be controlled by a HMI unit. An operator can enter the temperature, humidity, air flow, and differential air pressure set points values from the software. After the set points are determined by the operators, the controllers hold the system parameters at the desired set point values. The following experiments have been carried out to observe the performance of the controlled system.

As stated early, the responses of the controller depend on the outdoor climatic conditions. While the outdoor temperature was $21^{\circ} \mathrm{C}$, the system temperature increased from $28^{\circ} \mathrm{C}$ to

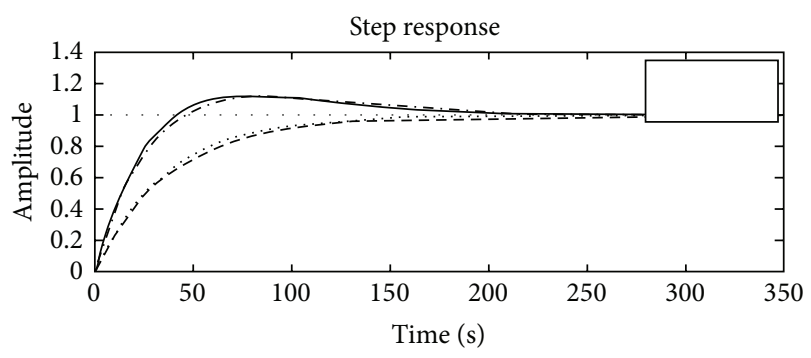

$$
\begin{array}{ll}
\ldots-\cdot \text { Ziegler-Nichols } & \ldots . . \text { Wang-Juang-Chan } \\
\text { C Cohen-Coon } & --- \text { IMC }
\end{array}
$$

FIGURE 9: Comparison of four PID controller methods.

$31^{\circ} \mathrm{C}$ in 12 minutes at the heating position. At same condition, the temperature decreased from $31^{\circ} \mathrm{C}$ to $28^{\circ} \mathrm{C}$ in only 5 minutes at the cooling position. The heating process was performed by return air circulation, so the heating process happened more slowly. The cooling process was performed by the fresh air. Therefore, the system response depends on the outdoor temperature as shown in Figure 12.

If the outdoor temperature is low, then the cooling process takes place as quickly; on the other side, if the outdoor temperature is high, then the cooling process is more slowly. If the set point of the temperature is determined as $32^{\circ} \mathrm{C}$ while the outdoor temperature is $34^{\circ} \mathrm{C}$, then the cooling processes take place very slowly and heating processes are more rapid as shown in Figure 12.

The cooling process utilizes the temperature of sprayed water by mixing the supplied air from outdoor. Humidity controller has been affected from the outdoor humidity ratio. But indeed humidification performance depends generally on the capacity of pumps, the structure of control systems, and units. Technical specification of the humidifier pumps in designed system is: the flow rate is $78 \mathrm{~m}^{3} / \mathrm{h}$, pump head rate is 3 bar, spray water flow rate is $78 \mathrm{~m}^{3} / \mathrm{h}$, nozzle pressure is 2.1 bar, maximum rotating speed is $3000 \mathrm{rpm}$, and nozzle diameter of each unit is $6 \mathrm{~mm}$.

Two experiments were done to test the performance of the humidity controller. The first experiment has been performed at the condition of $36 \%$ outdoor humidity ratios. The desired set point humidity has been obtained in 15 minutes. The humidity of the zone rose from $62 \%$ to $70 \%$ in this time interval. Decreasing the humidity again from $70 \%$ to $62 \%$ was carried out in 10 minutes as shown in Figure 13. The second experiment has been done at the $28 \%$ outdoor humidity ratio. The desired set point value has been reached in 18 minutes and the old humidity ratio has been reached in 8 minutes. Eventually, the humidity ratio is affected by outdoor humidity ratio as shown in Figure 13.

Differential pressure controller has been carried out by setting the speed of $37 \mathrm{~kW}$ exhaust fans according to measured value from differential air pressure transmitter. The differential pressure transmitter measures the difference between indoor and outdoor air pressure. Figure 14 shows the air pressure deviation measured from differential air pressure 


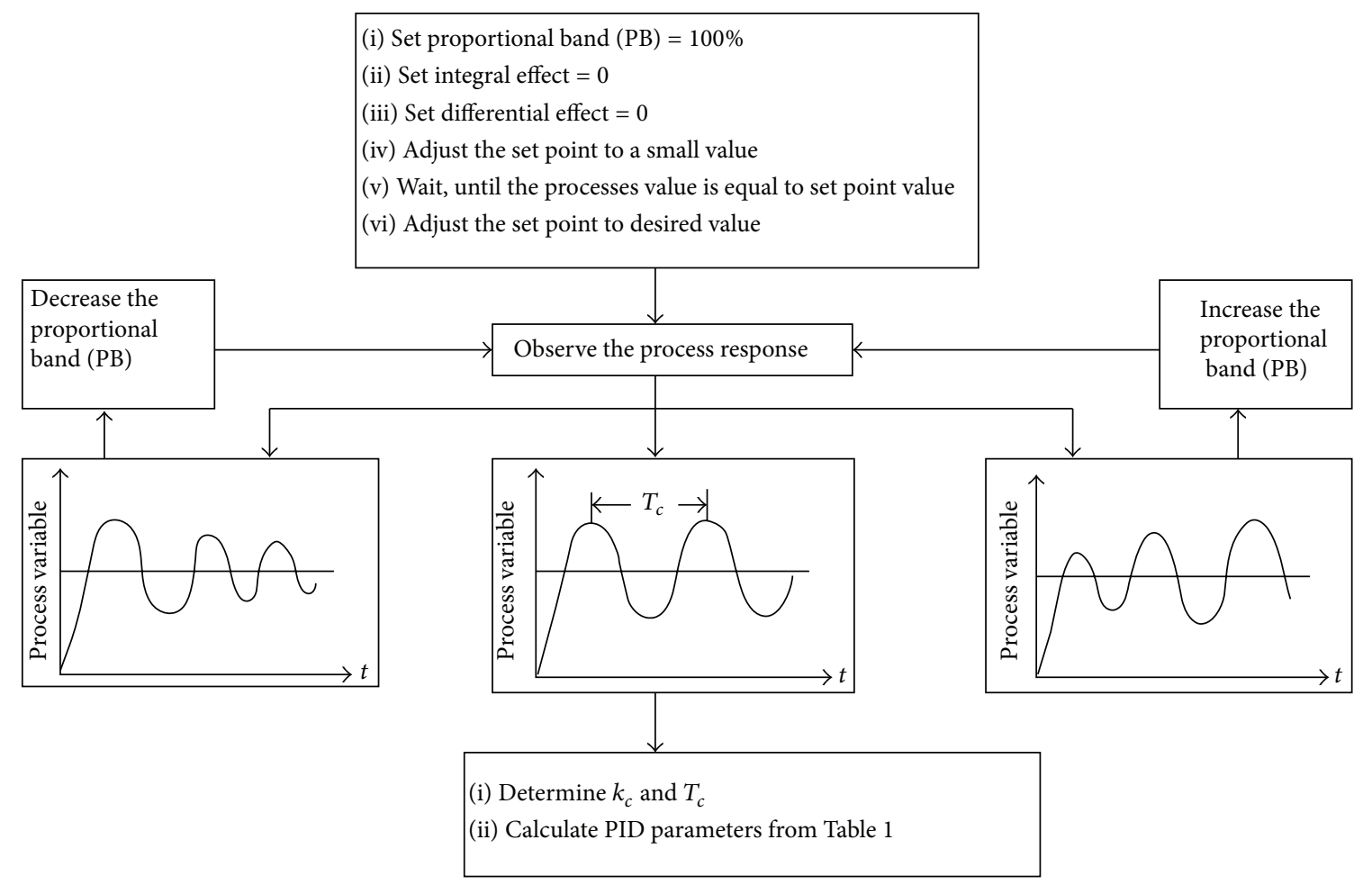

FIgURE 10: Z-N tuning based PID controller algorithm.

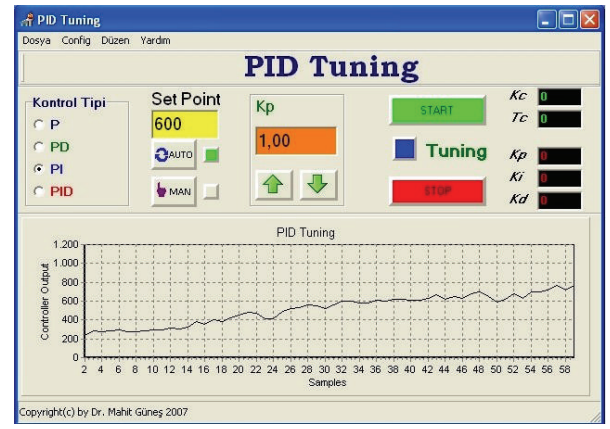

FIGURE 11: The developed Z-N tuning based PID tuning program.

transmitter during nine hours. The difference of the air pressure results from the event of clogging of exhaust filter and the difference air flow capacity between supply air from ventilation fans and exhaust air from exhaust fans. If the exhaust filter is clogged, the differential pressure transmitter warns operators and then the operator solves the filter problem and the filter clogging process does not affect differential pressure controller for a long time. That is, the differential pressure controller generally operates according to difference between air capacity of supply air and exhaust air.

Air flow capacity controller operates depending on the requirement of air changes of plant per second $\left(\mathrm{m}^{3} / \mathrm{s}\right)$. The air supplies using ventilation fans by adjusting its rotational speeds. Air flow capacity controller has the fast responses as shown in Figure 15. The desired maximum air capacity has been reached during only 10 seconds.
3.2. Comparison of Real and Simulation Systems. The unit step graphical responses of the derived approximate transfer function of the system were shown in Figure 9 for temperature controller. The designed real system temperature controller responses were shown in Figure 12. The desired level of the unit exchange of temperature has been obtained approximately within 180 seconds depending on the outdoor temperature by the designed controller. Model-based controller reached the same unit temperature level within 150-200 seconds depending on the PID parameters as shown in Figure 9. So, the results of the derived model and the real application system are approximately corresponding.

\section{Energy Saved in the Systems}

In the old conventional control system, exhaust and ventilating fans had been driven at constant speed. The differential pressure sensors, anemometers, and driver inverters for exhaust and ventilating fans have been added to the new designed control system. In this manner, the exhaust and ventilating fans' speed have been controlled depending on the requirements of the plant conditions. The expert operator only enters the desired parameters by the operator panel on the supervisory control system. Before the design of control system, the overall energy consumption was measured by using energy analyzer to determine the rate of energy efficiency of the designed four HVAC systems through Tables 6 to 9 which shows the amount of energy efficiency data for each controlled plant. Table 6 shows the energy consumptions for plant 1 , before and after the controller design. The 


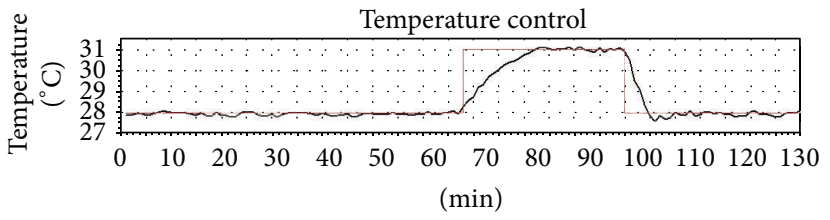

(a)

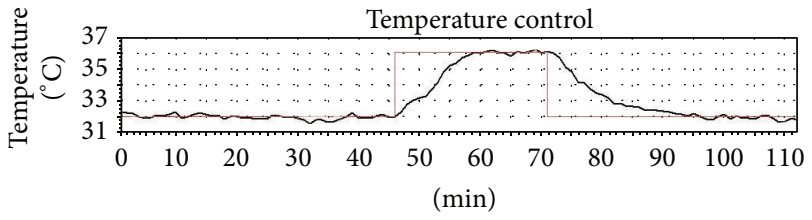

(b)

FIGURE 12: The temperature controller response of the outdoor condition at $21^{\circ} \mathrm{C}$ (a) and the temperature controller response of the outdoor condition at $34^{\circ} \mathrm{C}(\mathrm{b})$.

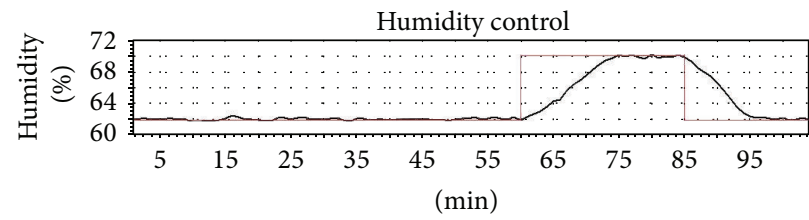

(a)

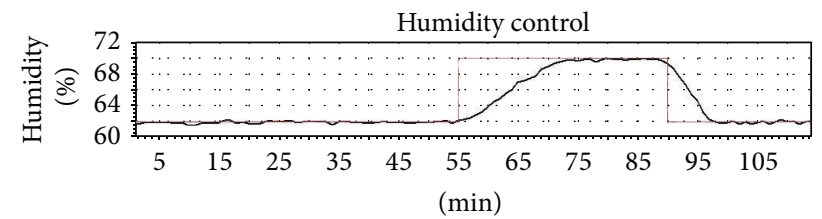

(b)

FIGURE 13: The humidity controller response of the outdoor condition at $36 \%$ humidity (a) and the humidity controller response of the outdoor condition at $28 \%$ humidity (b).

TABLE 6: Energy saving in plant 1.

\begin{tabular}{|c|c|c|c|c|c|}
\hline \multicolumn{3}{|c|}{ Power consumption in old conventional system } & \multicolumn{3}{|c|}{ Power consumption after the designed control system } \\
\hline Date & Hour & $\mathrm{kW}$ & Date & Hour & $\mathrm{kW}$ \\
\hline 14.11.2013 & 10:30:00 & 108.21 & 05.01.2014 & 19:00:00 & 59.08 \\
\hline 14.11.2013 & 11:00:00 & 109.53 & 05.01.2014 & 19:15:00 & 67.05 \\
\hline 14.11.2013 & 11:30:00 & 108.87 & 05.01.2014 & 19:30:00 & 65.72 \\
\hline 14.11.2013 & 12:00:00 & 109.2 & 05.01.2014 & 19:45:00 & 65.06 \\
\hline 14.11.2013 & 12:30:00 & 108.87 & 05.01 .2014 & 20:00:00 & 60.74 \\
\hline 14.11.2013 & 13:00:00 & 108.21 & 05.01.2014 & 20:15:00 & 65.72 \\
\hline 14.11 .2013 & $13: 30: 00$ & 108.87 & 05.01.2014 & 20:30:00 & 65.72 \\
\hline 14.11 .2013 & 14:00:00 & 108.54 & 05.01.2014 & $20: 45: 00$ & 65.39 \\
\hline 14.11 .2013 & $14: 30: 00$ & 108.87 & 05.01.2014 & 21:00:00 & 65.72 \\
\hline 14.11 .2013 & 15:00:00 & 108.54 & 05.01 .2014 & $21: 15: 00$ & 65.06 \\
\hline 14.11 .2013 & $15: 30: 00$ & 108.54 & 05.01.2014 & 21:30:00 & 67.05 \\
\hline 14.11 .2013 & $16: 00: 00$ & 109.2 & 05.01.2014 & 21:45:00 & 66.05 \\
\hline 14.11 .2013 & $16: 30: 00$ & 108.87 & 05.01.2014 & $22: 00: 00$ & 63.06 \\
\hline 14.11 .2013 & 17:00:00 & 109.53 & 05.01.2014 & $22: 15: 00$ & 65.72 \\
\hline 14.11.2013 & $17: 30: 00$ & 108.87 & 05.01.2014 & $22: 30: 00$ & 65.39 \\
\hline 14.11 .2013 & 18:00:00 & 109.53 & 05.01 .2014 & $22: 45: 00$ & 66.38 \\
\hline 14.11 .2013 & 18:30:00 & 109.2 & 05.01.2014 & 23:00:00 & 67.05 \\
\hline 14.11 .2013 & 19:00:00 & 105.55 & 05.01.2014 & $23: 15: 00$ & 66.38 \\
\hline 14.11 .2013 & 19:30:00 & 105.88 & 05.01.2014 & 23:30:00 & 65.39 \\
\hline 14.11 .2013 & 20:00:00 & 106.88 & 05.01 .2014 & $23: 45: 00$ & 66.05 \\
\hline 14.11 .2013 & 20:30:00 & 109.2 & 05.01.2014 & 00:00:00 & 66.05 \\
\hline 14.11 .2013 & 21:00:00 & 108.87 & 05.01.2014 & 00:15:00 & 65.39 \\
\hline 14.11.2013 & 21:30:00 & 108.87 & 05.01.2014 & 00:30:00 & 65.72 \\
\hline \multicolumn{2}{|c|}{ Average } & 108.55 & \multicolumn{2}{|c|}{ Average } & 65.26 \\
\hline
\end{tabular}

Average power consumption: old $=108.55$, new $=65.26$, and profit $=39.88 \%$. 
TABLE 7: Energy saving in plant 2.

\begin{tabular}{|c|c|c|c|c|c|}
\hline \multicolumn{3}{|c|}{ Power consumption in old conventional system } & \multicolumn{3}{|c|}{ Power consumption after the designed control system } \\
\hline Date & Hour & $\mathrm{kW}$ & Date & Hour & $\mathrm{kW}$ \\
\hline 13.07.2013 & 10:00:00 & 107.7 & 06.01 .2014 & 10:30:00 & 79.99 \\
\hline 13.07.2013 & 11:00:00 & 106.7 & 06.01 .2014 & 10:45:00 & 80.32 \\
\hline 13.07.2013 & 12:00:00 & 104.2 & 06.01 .2014 & 11:00:00 & 79.66 \\
\hline 13.07.2013 & 13:00:00 & 107.5 & 06.01 .2014 & 11:15:00 & 82.65 \\
\hline 13.07.2013 & 14:00:00 & 107.4 & 06.01 .2014 & 11:30:00 & 76.67 \\
\hline 13.07.2013 & 15:00:00 & 107,7 & 06.01 .2014 & $11: 45: 00$ & 75.35 \\
\hline 13.07 .2013 & 16:00:00 & 108.3 & 06.01.2014 & 12:00:00 & 75.01 \\
\hline 13.07.2013 & 17:00:00 & 108 & 06.01 .2014 & $12: 15: 00$ & 71.36 \\
\hline 13.07.2013 & 18:00:00 & 108.4 & 06.01 .2014 & $12: 30: 00$ & 72.03 \\
\hline 13.07.2013 & 19:00:00 & 108.2 & 06.01 .2014 & $12: 45: 00$ & 71.69 \\
\hline 13.07 .2013 & 20:00:00 & 107.9 & 06.01 .2014 & 13:00:00 & 71.69 \\
\hline 13.07 .2013 & 21:00:00 & 107.9 & 06.01.2014 & $13: 15: 00$ & 72.03 \\
\hline 13.07 .2013 & 22:00:00 & 108.4 & 06.01.2014 & $13: 30: 00$ & 74.02 \\
\hline 13.07.2013 & 23:00:00 & 107.8 & 06.01.2014 & $13: 45: 00$ & 74.68 \\
\hline 13.07.2013 & 00:00:00 & 107.9 & 06.01 .2014 & 14:00:00 & 74.68 \\
\hline 13.07 .2013 & 01:00:00 & 107.2 & 06.01.2014 & $14: 15: 00$ & 75.68 \\
\hline 13.07 .2013 & 02:00:00 & 106.7 & 06.01.2014 & $14: 30: 00$ & 75.01 \\
\hline 13.07 .2013 & 03:00:00 & 106.3 & 06.01.2014 & $14: 45: 00$ & 76.34 \\
\hline 13.07.2013 & 04:00:00 & 106.5 & 06.01 .2014 & 15:00:00 & 74.68 \\
\hline 13.07.2013 & 05:00:00 & 106.8 & 06.01 .2014 & $15: 15: 00$ & 75.35 \\
\hline 13.07 .2013 & 06:00:00 & 106.8 & 06.01.2014 & $15: 30: 00$ & 75.35 \\
\hline 13.07 .2013 & 07:00:00 & 106.2 & 06.01.2014 & $15: 45: 00$ & 75.01 \\
\hline 13.07 .2013 & 08:00:00 & 106.2 & 06.01.2014 & $16: 00: 00$ & 75.01 \\
\hline \multicolumn{2}{|c|}{ Average } & 107.25 & \multicolumn{2}{|c|}{ Average } & 75.4 \\
\hline
\end{tabular}

Average power consumption: old $=107.25$, new $=75.40$, and profit $=29.69 \%$.

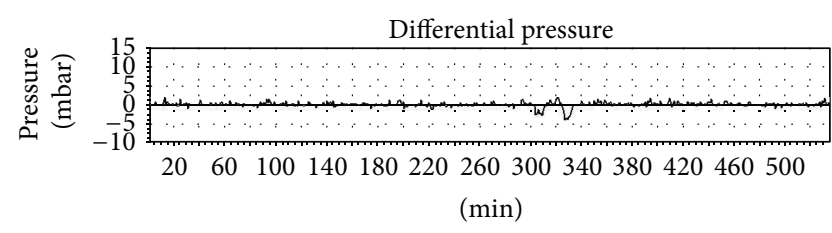

FIGURE 14: The differential air pressure of supply and exhaust air in the period of 9 hours.

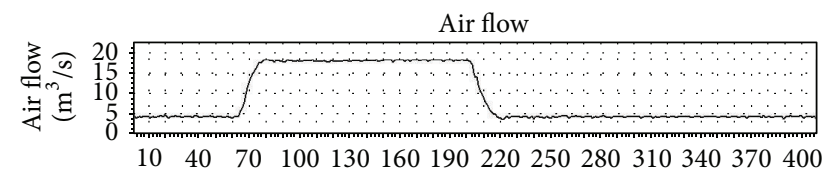

(s)

FIGURE 15: The air flow capacity controller response.

energy consumption in old conventional control system for plant 1 was measured as the average of $108 \mathrm{~kW}$. For the energy consumption in the new designed system, this value was decreased to average of $65 \mathrm{~kW}$. The energy efficiency has been obtained as $43 \mathrm{~kW}$ per hour for plant 1 . The energy efficiency of $32 \mathrm{~kW}$ has been obtained for plant 2, $41 \mathrm{~kW}$ in plant 3 , and $24 \mathrm{~kW}$ in plant 4 , respectively. The money spent for plant 1 , plant 2, and plant 3 was approximately 39450 USD and 8331 USD for plant 4 . The total energy efficiency has been measured as $140 \mathrm{~kW}$. The total cost of 47781 USD has been spent of the whole system.

\section{Conclusion}

This paper describes a novel simulation-optimization technique that was applied to devise a reset scheme of air flow for air temperatures and differential air pressure for supply and exhaust air of the HVAC control system in fabric manufacturing plants in industry. Due to the complex relationship of the HVAC system parameters, it is necessary to suggest optimum settings for different operations in response to the dynamic cooling loads and changing weather conditions during a year. Proportional-integral-derivative (PID) programming was developed which can effectively handle the discrete, nonlinear, and highly constrained optimization problems. To solve this problem, a HVAC control system has been successfully designed and the dynamic model of the controlled zone has been derived accurately for an integrated big plant in Turkey. 
TABLE 8: Energy saving in plant 3.

\begin{tabular}{|c|c|c|c|c|c|}
\hline \multicolumn{3}{|c|}{ Power consumption in old conventional system } & \multicolumn{3}{|c|}{ Power consumption after the designed control system } \\
\hline Date & Hour & $\mathrm{kW}$ & Date & Hour & $\mathrm{kW}$ \\
\hline 16.11.2013 & 10:30:00 & 85.64 & 06.01 .2014 & 18:00:00 & 43.81 \\
\hline 16.11.2013 & 11:00:00 & 85.3 & 06.01 .2014 & 18:30:00 & 43.81 \\
\hline 16.11.2013 & 11:30:00 & 85.64 & 06.01 .2014 & 19:00:00 & 43.48 \\
\hline 16.11.2013 & 12:00:00 & 84.97 & 06.01 .2014 & 19:30:00 & 42.82 \\
\hline 16.11.2013 & $12: 30: 00$ & 84.97 & 06.01 .2014 & 20:00:00 & 43.15 \\
\hline 16.11 .2013 & 13:00:00 & 84.97 & 06.01 .2014 & $20: 30: 00$ & 48.13 \\
\hline 16.11 .2013 & $13: 30: 00$ & 84.97 & 06.01 .2014 & 21:00:00 & 43.48 \\
\hline 16.11 .2013 & 14:00:00 & 83.64 & 06.01 .2014 & 21:30:00 & 43.81 \\
\hline 16.11 .2013 & $14: 30: 00$ & 84.31 & 06.01.2014 & $22: 00: 00$ & 40.83 \\
\hline 16.11 .2013 & 15:00:00 & 83.98 & 06.01 .2014 & $22: 30: 00$ & 42.15 \\
\hline 16.11 .2013 & $15: 30: 00$ & 83.64 & 06.01 .2014 & 23:00:00 & 49.12 \\
\hline 16.11 .2013 & $16: 00: 00$ & 83.64 & 06.01 .2014 & $23: 30: 00$ & 43.81 \\
\hline 16.11 .2013 & $16: 30: 00$ & 83.64 & 06.01.2014 & 00:00:00 & 43.15 \\
\hline 16.11.2013 & $17: 00: 00$ & 83.64 & 06.01 .2014 & 00:30:00 & 44.81 \\
\hline 16.11 .2013 & $17: 30: 00$ & 83.64 & 06.01 .2014 & 01:00:00 & 39.5 \\
\hline 16.11 .2013 & 18:00:00 & 83.64 & 06.01 .2014 & 01:30:00 & 43.81 \\
\hline 16.11 .2013 & $18: 30: 00$ & 83.31 & 06.01 .2014 & 02:00:00 & 39.5 \\
\hline 16.11 .2013 & 19:00:00 & 83.98 & 06.01 .2014 & 02:30:00 & 44.15 \\
\hline 16.11 .2013 & $19: 30: 00$ & 83.64 & 06.01 .2014 & 03:00:00 & 36.51 \\
\hline 16.11 .2013 & 20:00:00 & 83.64 & 06.01 .2014 & 03:30:00 & 38.83 \\
\hline 16.11 .2013 & 20:30:00 & 83.98 & 06.01.2014 & 04:00:00 & 41.16 \\
\hline 16.11 .2013 & 21:00:00 & 84.31 & 06.01 .2014 & 04:30:00 & 42.15 \\
\hline 16.11.2009 & 21:30:00 & 83.98 & 06.01 .2014 & 05:00:00 & 38.83 \\
\hline \multicolumn{2}{|c|}{ Average } & 84.22 & \multicolumn{2}{|c|}{ Average } & 42.64 \\
\hline
\end{tabular}

Average power consumption: old $=84.22$, new $=42.64$, and profit $=49.37 \%$.

The simulation and the real controller responses have been observed, respectively. When the results have been compared, either of the system responses has been obtained similarly. Supervisory control software was developed to control overall system using a host computer and programmable controllers. All of the control units could communicate with the host computer by the MODBUS TCP/IP Ethernet protocol. Thus, the system parameters could be observed and controlled on the single central point by the host computer and an operator.

The approximately $40 \%$ energy efficiency was gained by the designed control system. This energy efficiency amount was clearly verified by measuring of energy consumption of each plant as shown in Table 6 through Table 9. Finally the following beneficial results have been obtained:

(i) total money spent to control system $=47781 \$$;

(ii) total energy efficiency per hour $=140 \mathrm{~kW}$;

(iii) $1 \mathrm{~kW}$ electricity cost $=0.087 \$ / \mathrm{kWh}$;

(iv) energy efficiency per month $=140 \mathrm{kWh} * 24$ hours $*$ 30 days $* 0.087 \$ / \mathrm{kWh}=8770 \$$;

(v) depreciation time of the system $=47781 / 8770=5.44$ months.

\section{Nomenclature}

$f_{a}: \quad$ Volume flow rate of air $\left(\mathrm{m}^{3} / \mathrm{s}\right)$

$c_{p}: \quad$ Specific heat capacity of air $\left(\mathrm{kJ} / \mathrm{kg} \cdot{ }^{\circ} \mathrm{C}\right)$

$\rho_{a}: \quad$ Mass density of air $\left(\mathrm{kg} / \mathrm{m}^{3}\right)$

$v_{z}: \quad$ Volume of the zone $\left(\mathrm{m}^{3}\right)$

ACH: Air changes per hour

$h$ : Convection heat transfer coefficient, $\left(\mathrm{W} / \mathrm{m}^{2} \cdot{ }^{\circ} \mathrm{C}\right)$

$h_{w}: \quad$ Rate of moisture air produced in air humidifier

$k_{h}$ : Conduction heat transfer coefficient $\left(\mathrm{W} / \mathrm{m} \cdot{ }^{\circ} \mathrm{C}\right)$

$k$ : $\quad$ Gain coefficient $\left({ }^{\circ} \mathrm{C} \cdot \mathrm{s} / \mathrm{kg}\right)$

$\varepsilon: \quad$ Emissivity constant

$\sigma: \quad$ Boltzmann constant $\left(\mathrm{W} / \mathrm{m}^{2} \cdot{ }^{\circ} \mathrm{C}\right)$

$m: \quad$ Mass flow rates

$C_{h}$ : Overall thermal capacitance of the humidifier

$T_{h}: \quad$ Supply air temperature $\left({ }^{\circ} \mathrm{C}\right)$

$\alpha_{h}$ : Overall transmittance area factor of the humidifier $\left(\mathrm{kJ} / \mathrm{s} .{ }^{\circ} \mathrm{C}\right)$

$v_{z h}: \quad$ Volume of humidifier

$w_{h}: \quad$ Supply air humidity ratio $(\mathrm{kg} / \mathrm{kg})$ 
TABLE 9: Energy saving in plant 4.

\begin{tabular}{|c|c|c|c|c|c|}
\hline \multicolumn{3}{|c|}{ Power consumption in old conventional system } & \multicolumn{3}{|c|}{ Power consumption after the designed control system } \\
\hline Date & Hour & $\mathrm{kW}$ & Date & Hour & $\mathrm{kW}$ \\
\hline 17.11.2013 & $10: 30: 00$ & 46.8 & 07.01.2014 & 11:00:00 & 22.24 \\
\hline 17.11.2013 & 11:00:00 & 46.8 & 07.01.2014 & 11:15:00 & 22.24 \\
\hline 17.11.2013 & $11: 30: 00$ & 46.47 & 07.01.2014 & 11:30:00 & 22.24 \\
\hline 17.11.2013 & 12:00:00 & 46.47 & 07.01.2014 & $11: 45: 00$ & 22.24 \\
\hline 17.11.2013 & $12: 30: 00$ & 46.47 & 07.01.2014 & 12:00:00 & 20.25 \\
\hline 17.11.2013 & 13:00:00 & 47.8 & 07.01.2014 & $12: 15: 00$ & 19.92 \\
\hline 17.11.2013 & $13: 30: 00$ & 44.81 & 07.01.2014 & $12: 30: 00$ & 19.92 \\
\hline 17.11.2013 & 14:00:00 & 46.47 & 07.01.2014 & $12: 45: 00$ & 22.24 \\
\hline 17.11.2013 & $14: 30: 00$ & 46.47 & 07.01.2014 & 13:00:00 & 22.24 \\
\hline 17.11.2013 & 15:00:00 & 45.81 & 07.01.2014 & $13: 15: 00$ & 22.24 \\
\hline 17.11.2013 & $15: 30: 00$ & 45.81 & 07.01.2014 & $13: 30: 00$ & 22.24 \\
\hline 17.11.2013 & $16: 00: 00$ & 46.47 & 07.01.2014 & $13: 45: 00$ & 22.24 \\
\hline 17.11.2013 & $16: 30: 00$ & 46.14 & 07.01.2014 & 14:00:00 & 22.24 \\
\hline 17.11.2013 & 17:00:00 & 45.81 & 07.01.2014 & $14: 15: 00$ & 22.24 \\
\hline 17.11.2013 & $17: 30: 00$ & 43.81 & 07.01.2014 & $14: 30: 00$ & 23.9 \\
\hline 17.11.2013 & 18:00:00 & 45.81 & 07.01.2014 & $14: 45: 00$ & 22.24 \\
\hline 17.11.2013 & $18: 30: 00$ & 45.14 & 07.01.2014 & 15:00:00 & 22.24 \\
\hline 17.11.2013 & 19:00:00 & 45.14 & 07.01.2014 & $15: 15: 00$ & 22.24 \\
\hline 17.11.2013 & 19:30:00 & 45.14 & 07.01.2014 & $15: 30: 00$ & 22.24 \\
\hline 17.11 .2013 & 20:00:00 & 45.47 & 07.01.2014 & $15: 45: 00$ & 19.92 \\
\hline 17.11.2013 & $20: 30: 00$ & 45.47 & 07.01 .2014 & 16:00:00 & 20.25 \\
\hline 17.11.2013 & 21:00:00 & 43.48 & 07.01.2014 & $16: 15: 00$ & 21.78 \\
\hline 17.11.2013 & 21:30:00 & 45.14 & 07.01.2014 & $16: 30: 00$ & 21.78 \\
\hline \multicolumn{2}{|c|}{ Average } & 45.79 & & & 21.8 \\
\hline
\end{tabular}

Average power consumption: old $=45.79$, new $=21.80$, and profit $=52.39 \%$.

$w_{\text {sa }}:$ Humidity ratio of supply air $(\mathrm{kg} / \mathrm{kg})$

$\tau$ : Time constant

L: $\quad$ Time delay.

\section{Conflict of Interests}

The author declares that there is no conflict of interests regarding the publication of this paper.

\section{References}

[1] G. P. Henze, D. E. Kalz, S. Liu, and C. Felsmann, "Experimental analysis of model-based predictive optimal control for active and passive building thermal storage inventory," HVAC\&R Research, vol. 11, no. 2, pp. 189-213, 2005.

[2] W. Z. Huang, M. Zaheeruddin, and S. H. Cho, "Dynamic simulation of energy management control functions for HVAC systems in buildings," Energy Conversion and Management, vol. 47, no. 7-8, pp. 926-943, 2006.

[3] S. Soyguder and H. Alli, "An expert system for the humidity and temperature control in HVAC systems using ANFIS and optimization with Fuzzy Modeling Approach," Energy and Buildings, vol. 41, no. 8, pp. 814-822, 2009.

[4] B. Tashtoush, M. Molhim, and M. Al-Rousan, "Dynamic model of an HVAC system for control analysis," Energy, vol. 30, no. 10, pp. 1729-1745, 2005.
[5] J. Teeter and M.-Y. Chow, "Application of functional link neural network to hvac thermal dynamic system identification," IEEE Transactions on Industrial Electronics, vol. 45, no. 1, pp. 170-176, 1998.

[6] J. Wang, C. Zhang, and Y. Jing, "Fuzzy immune self-tuning pid control of HVAC system," in Proceedings of the IEEE International Conference on Mechatronics and Automation (ICMA '08), pp. 678-683, Takamatsu, Japan, August 2008.

[7] K. F. Fong, V. I. Hanby, and T. T. Chow, "HVAC system optimization for energy management by evolutionary programming," Energy and Buildings, vol. 38, no. 3, pp. 220-231, 2006.

[8] A. P. Wemhoff, "Application of optimization techniques on lumped HVAC models for energy conservation," Energy and Buildings, vol. 42, no. 12, pp. 2445-2451, 2010.

[9] S. Lee, M. J. Kim, S. H. Pyo, J. T. Kim, and C. K. Yoo, "Evaluation of an optimal ventilation IAQ control strategy using control performance assessment and energy demand," Energy and Buildings, 2014.

[10] R. C. Panda, "Synthesis of PID controller for unstable and integrating processes," Chemical Engineering Science, vol. 64, no. 12, pp. 2807-2816, 2009.

[11] S. Skogestad, "Simple analytic rules for model reduction and PID controller tuning," Journal of Process Control, vol. 13, no. 4, pp. 291-309, 2003.

[12] K. J. Åström and T. Hägglund, "The future of PID control," Control Engineering Practice, vol. 9, no. 11, pp. 1163-1175, 2001. 
[13] K. J. Åström and T. Hägglund, "Revisiting the Ziegler-Nichols step response method for PID control," Journal of Process Control, vol. 14, no. 6, pp. 635-650, 2004.

[14] W. K. Ho, O. P. Gan, E. B. Tay, and E. L. Ang, "Performance and gain and phase margins of well-known PID tuning formulas," IEEE Transactions on Control Systems Technology, vol. 4, no. 4, pp. 473-477, 1996.

[15] S. W. Sung, J. Lee, and I. B. Lee, Process Identification and PID Control, John Wiley \& Sons, New York, NY, USA, 2009.

[16] L. Hongli, D. Peiyong, and J. Lei, "A novel fuzzy controller design based-on PID Gains for HVAC systems," in Proceedings of the 7th World Congress on Intelligent Control and Automation (WCICA '08), pp. 736-739, IEEE, Chongqing, China, June 2008.

[17] K. F. Fong, V. I. Hanby, and T. T. Chow, "System optimization for HVAC energy management using the robust evolutionary algorithm," Applied Thermal Engineering, vol. 29, no. 11-12, pp. 2327-2334, 2009.

[18] D. Xue, Y. Q. Chen, and D. P. Atherton, Linear Feedback Control, SIAM's Advances in Design and Control, SIAM, Philadelphia, Pa, USA, 2007.

[19] N. J. Killingsworth and M. Krstic, "PID tuning using extremum seeking: online, model-free performance optimization," IEEE Control Systems Magazine, vol. 26, no. 1, pp. 70-79, 2006. 

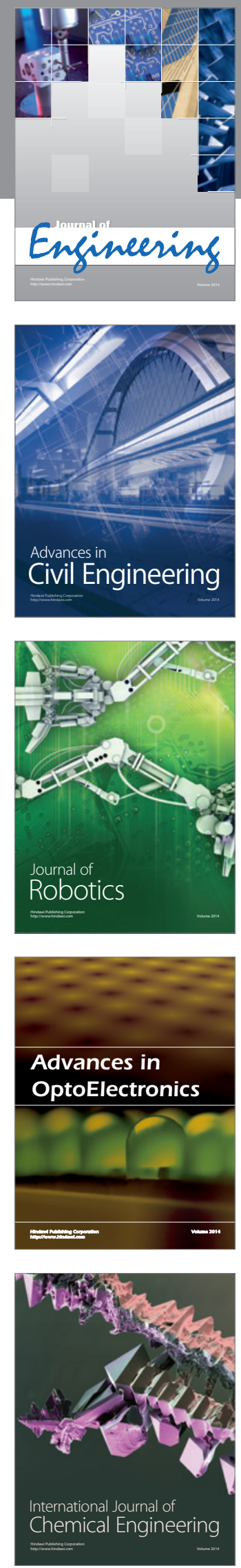

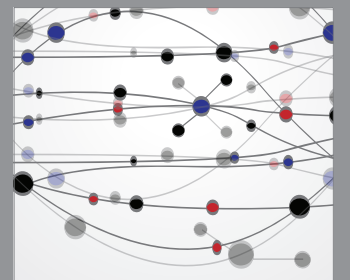

The Scientific World Journal
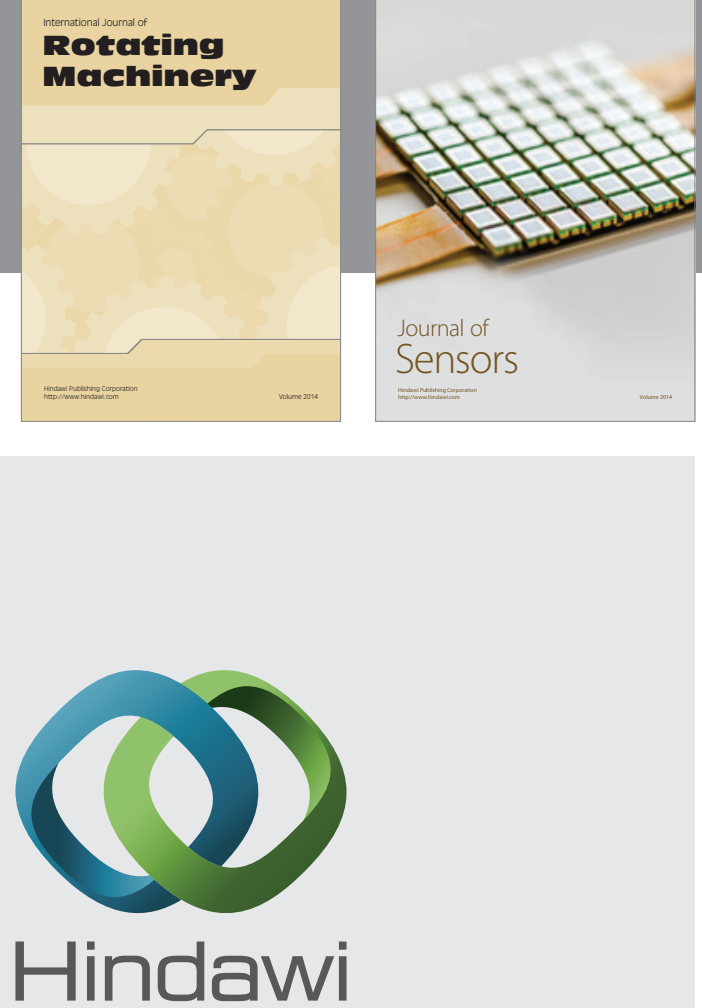

Submit your manuscripts at http://www.hindawi.com
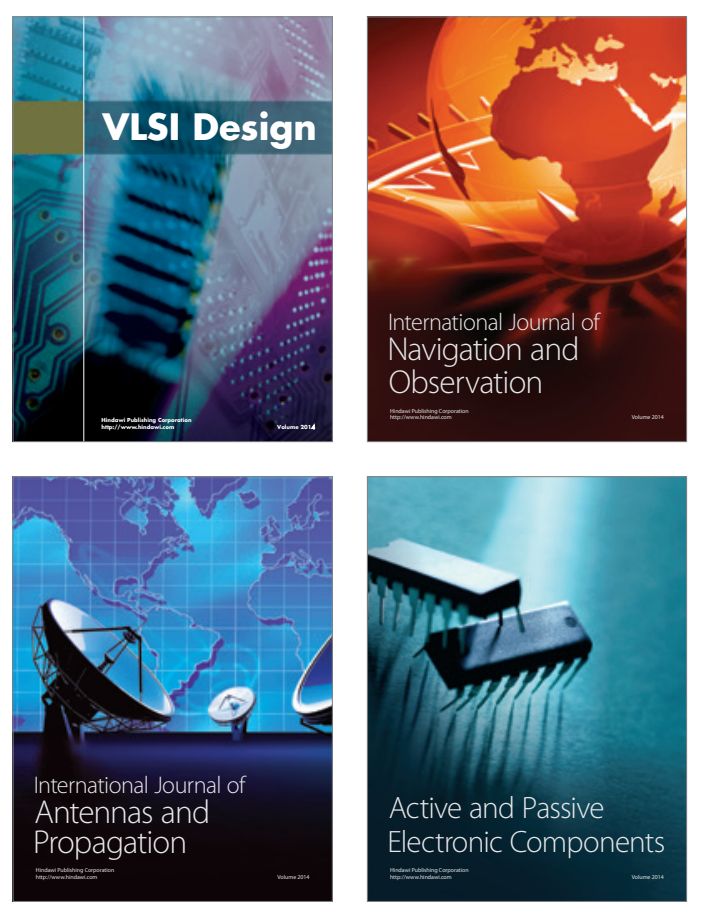
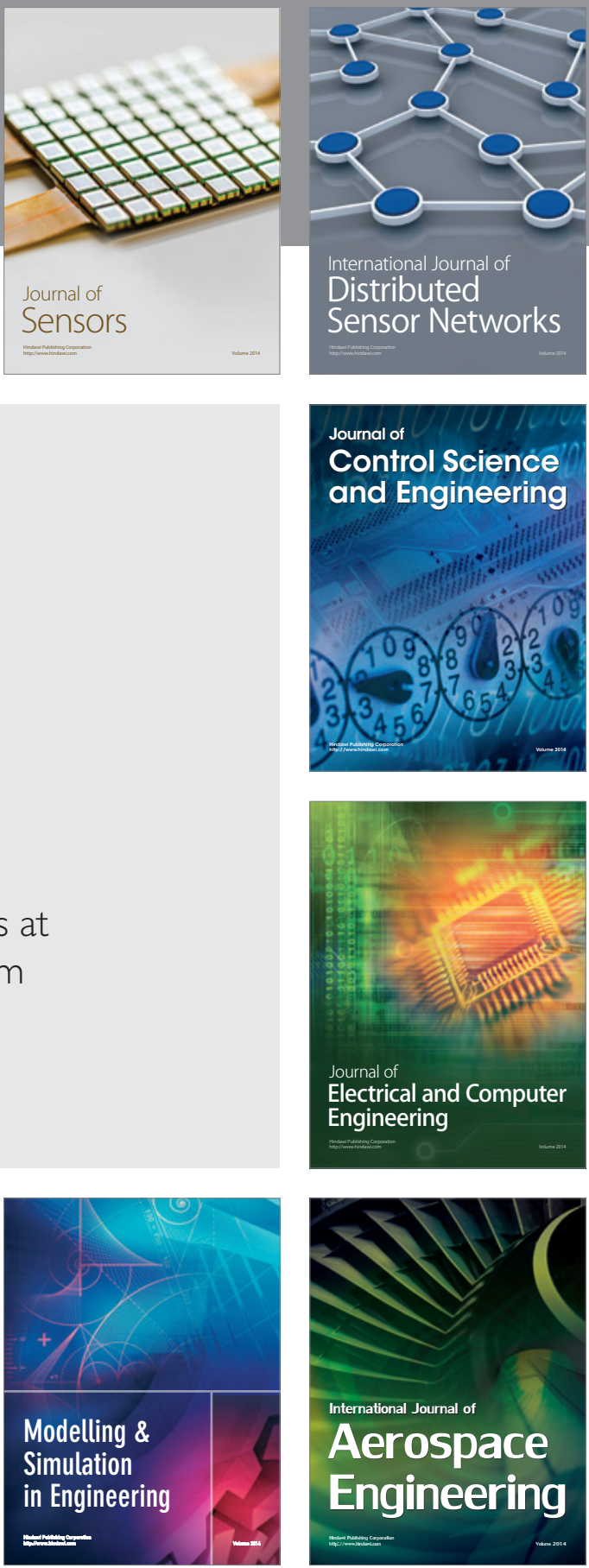

Journal of

Control Science

and Engineering
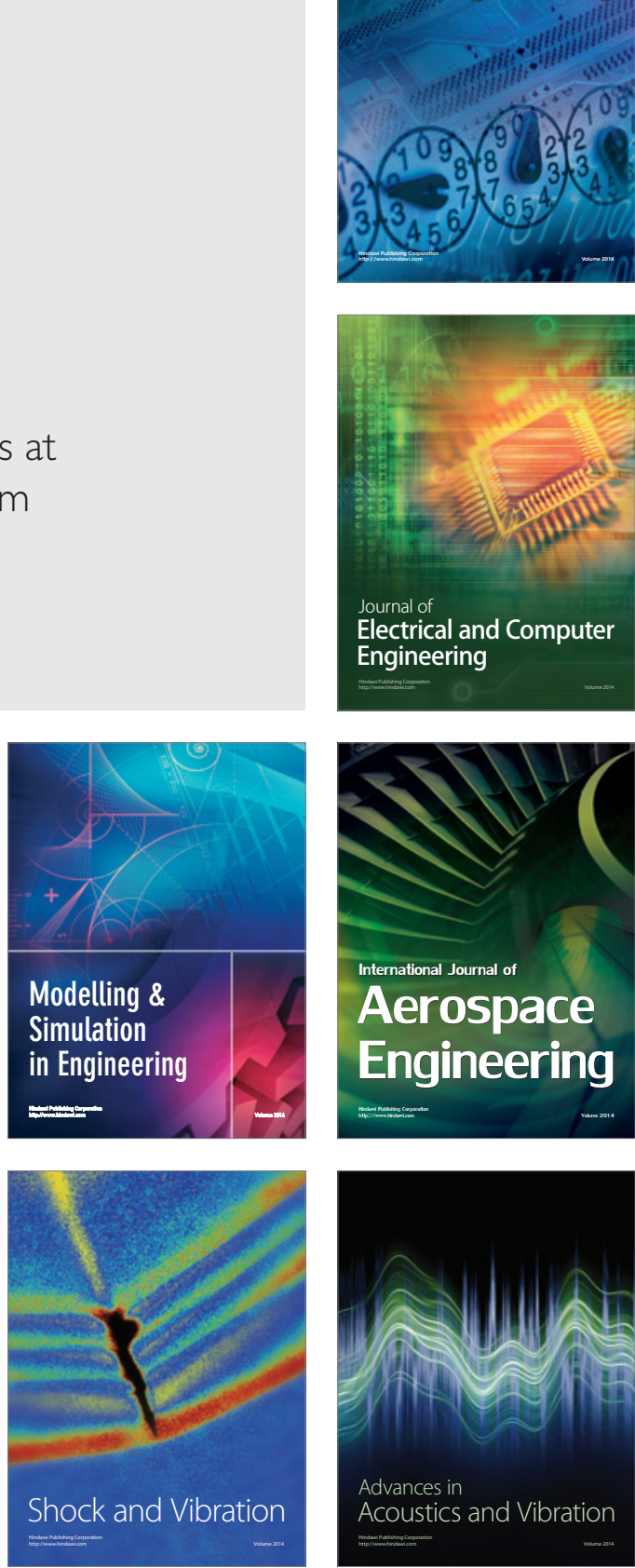